\title{
AN ONLINE CHAT BETWEEN FRANK FU AND MR BALD \\ Frank Fu
}

Wake up and open the curtain. It's another cloudy wet day in LA.

What's going on? Shit!

Strapping on my Soviet-looking Zodiac Astrographic Blue Edition watch, I turn on the Huawei P30 Pro and start flipping through @zenmasterfu on Instagram.

It's been two years since I did "Sleep with Frank Fu," a project at the 2017 Venice Biennale. Had a fantastic time there with my multi-cosmic entourage, not to mention spending a lot of time with my dear friend, Tehching Hsieh.

Ding! A message pops up on the screen:

Mr Bald: Frank! Are you at Venice this year?

FU: Yes, but not physically.

Mr Bald: What do you mean?

FU: My project at Venice this year is called "What is Venice Biennale when Frank Fu is Absent?"

Mr Bald: Are you really absent? Seems to me you're somehow still here.

FU: Yeah, too much sleeping around in Venice last time.

Mr Bald: Mmm ... I guess what happens in Venice stays in Venice.

FU: Congrats again on being the Top 100 Most Powerful People in the Art World.

Mr Bald: Thanks Frank! So what have you been really up to?

FU: It's been four days since I came back from my Scandi Tour - The Curator's Buttplug gig in Norway was sexysublime! Been eight months since the artist residency gig with my cosmic twin collaborator Yves Gore at Dunedin School of Art in New Zealand. In between, when I don't have my hands full with FU Institute, I showed a couple of my films at some dark 'n' edgy film clubs in Jakarta and Bali, performed Art NOT Fair in LA, and gave a lecture called FLUXFU at University of Southern California.

Mr Bald: Scheisse! What a live-running CV from hell. What's going on in your head, Frank?! I'd say it's from a rather over-inflated ego getting in the way, big time.

FU: But, that's what I do as a contemporary artist. Perform, make films, give lectures, travel, have artist residencies, so on and so forth, plus constantly getting messages from Facebook and Instagram.

Ding! Here we go, another notification pops up on my screen. D... E... L... E...T... E... 
Mr Bald: Are you insinuating hard work with a heavy dose of smart-arsed stupidity is the answer?!

FU: Shit! My Zodiac stops working again. I thought Swiss-made things are supposed to last forever. Even my Dita glasses have passed the ten-year mark! And it's not even Swiss.

Mr Bald: What am I, a watchmaker? How'd I know?

FU: Aren't you Swiss?

Mr Bald: Let's get back to your Scandi Tour in Sweden. What were you doing there?

FU: From Gothenburg to Stockholm; from street market, shopping mall to galleries; from one tram to another; from homeless, to police to royal guards; from destruction to reconstruction, and from your saliva to mine.

Mr Bald: Mmm ... but why Sweden?

FU: Under the global extremely difficult and troubling gig economy, it's much cheaper to fly from LA to Sweden via Norwegian Airlines.

Mr Bald: Right.

FU: I was also looking for that Neo-Nazi, so called Nordic Resistance Movement. They usually form a human circle on the streets of Stockholm and I wanted to put myself in the middle of them, and start reading Deleuze and the City.

Mr Bald: Did you do it?

FU: Couldn't find them! My friend saw them though. He took a picture of them at a square in Stockholm. I'm thinking maybe Yves could photoshop me reading the book standing among those fascists.

Mr Bald: Photoshop, some kind of digital intervention? I love it!

FU: Yeah, just like how Kardashian got her big butt. You know, it looks quite real.

Mr Bald: What was your budget this time? Still scooping ice-creams for six months?

FU: It's getting harder and harder to scoop ice-creams these days, with the US-China trade war happening. You think I should become a dog-walker? Lots of dogs around my neighbourhood. Good money! Though they do piss and shit a lot.

Mr Bald: What happened to FU Institute? I thought you're making enough bucks from it.

FU: What about your Brutally Early Club? You must be getting big bucks from it too. Since it's brutally early, people must be getting blue balls, and having to wear strap-ons just to show how enthusiastic they are about your club.

Mr Bald: You know Frank I'm over 50, so I don't think that way anymore. I usually just find a way to deal with it when Mr Bland comes home.

FU: Or, maybe, you just need some Rhino suction.

Mr Bald: I'm too busy for that shit.

FU: Me too.

Mr Bald: Somehow I think the purpose of FU Institute's actions around the world functions like a fan-gathering machine. Don't you agree? 
FU: Mac, Huawei, Dita, Ecco. For Cultural Purposes Only, No Commercial Value. Human gathering, animal gathering, dialoguing, discussing, interacting, communicating, caring, supporting, hugging, touching, kissing, sexing. You can find out more about the FU movement through @fuinstitute on Facebook and Instagram, especially my Finnish-SwedishNorwegian sweater with three nipples. Love it!

Mr Bald: Scheisse. Gotta make tracks ... Ciao bello!

FU: Bella Ciao!

The Zodiac is still not working. I get up from my chair, open a drawer, take out my limited edition Swatch - printed with Franz Marc's The Dream painting - and strap it on! A sense of time rises. Thanks for the birthday present Yves! It's punctual, accurate, yet it ticks so fucking loud.

FUCK ME.

Born in Inner Mongolia, China, Frank Fu is a contemporary artist. His work challenges the white box settings of galleries and museums, and his endurance performances and interventions examine his identity as an artist, often commenting on the politics of the art world. His work has been shown at the Venice Biennale, Documenta, the Sydney Biennale, Asian Contemporary Art Fair (New York), Asian Contemporary Art Week (New York), Rubin Museum of Art (New York), Centre Pompidou (Paris), Locarno Film Festival, Vision Du Réel (Switzerland) and Transcinema (Peru). Frank Fu has also been featured on networks and publications such as NHK (Japan), CCTV4 (China), ARTCO (Taiwan), The National Business Review, the New Zealand Herald, the New Zealand Listener, Frieze and TateShots. Frank Fu is the founder and head of school at FU INSTITUTE. He currently lives and works in Los Angeles.

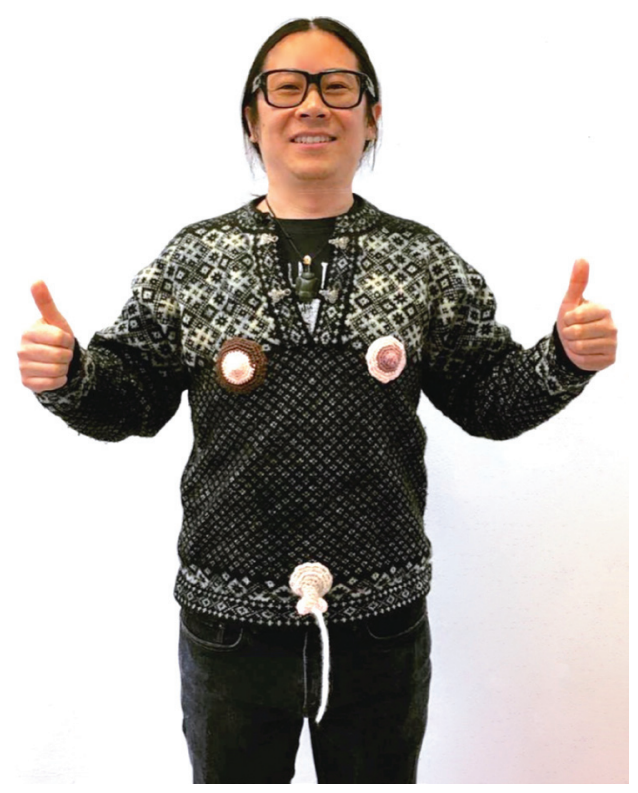

Figure I. Frank Fu and his three nipples. 


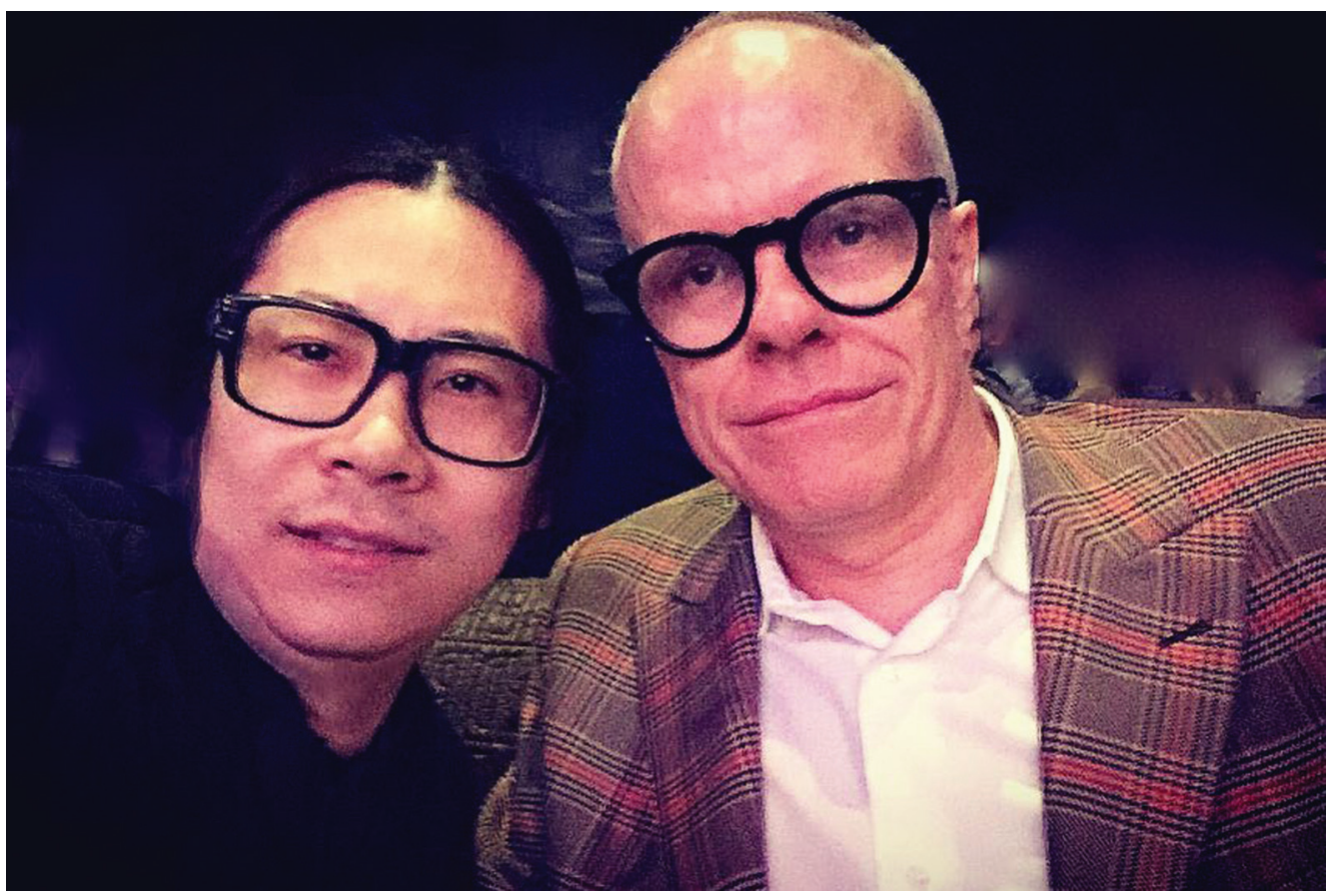

Figure 2. What Happens in Venice stays in Venice.

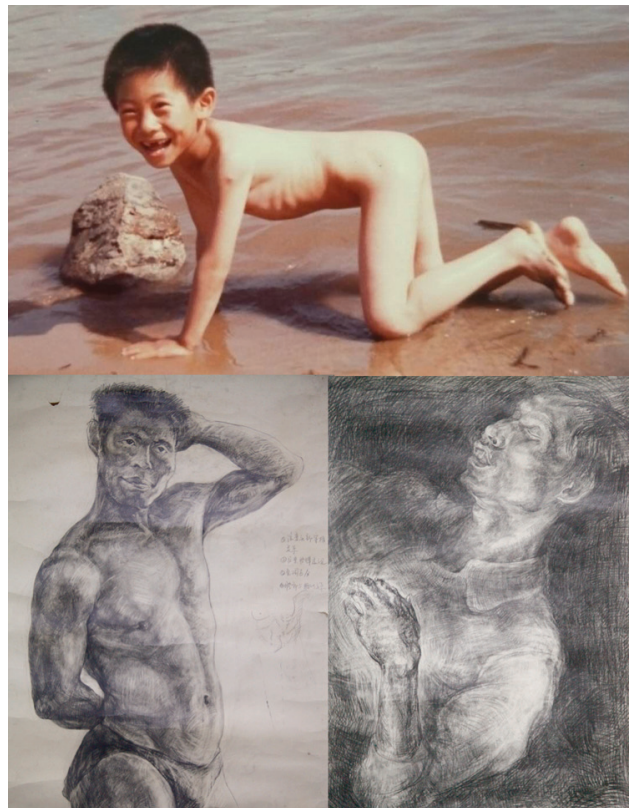

Figure 3. Long Life Your Milk.

\section{a cryptic journey into Norwegian's}

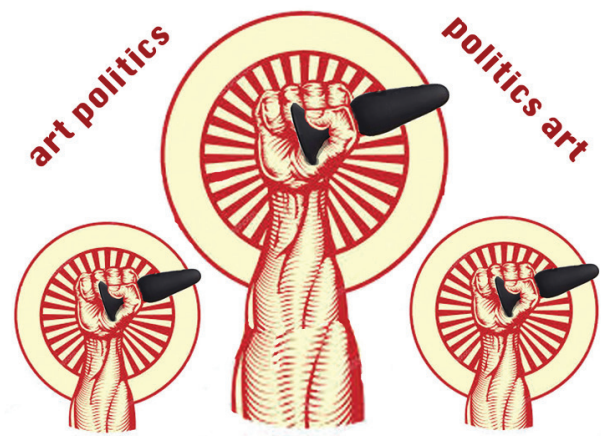

F R A N K F U

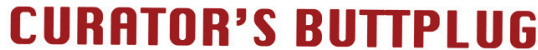

stavanger | velferden | kunstskolen i rogaland

17 th - 30 th FPRIL 2019

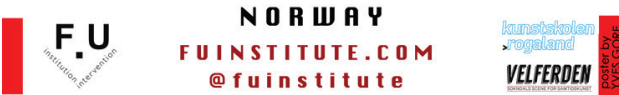

Figure 4. Curators Buttplug. 


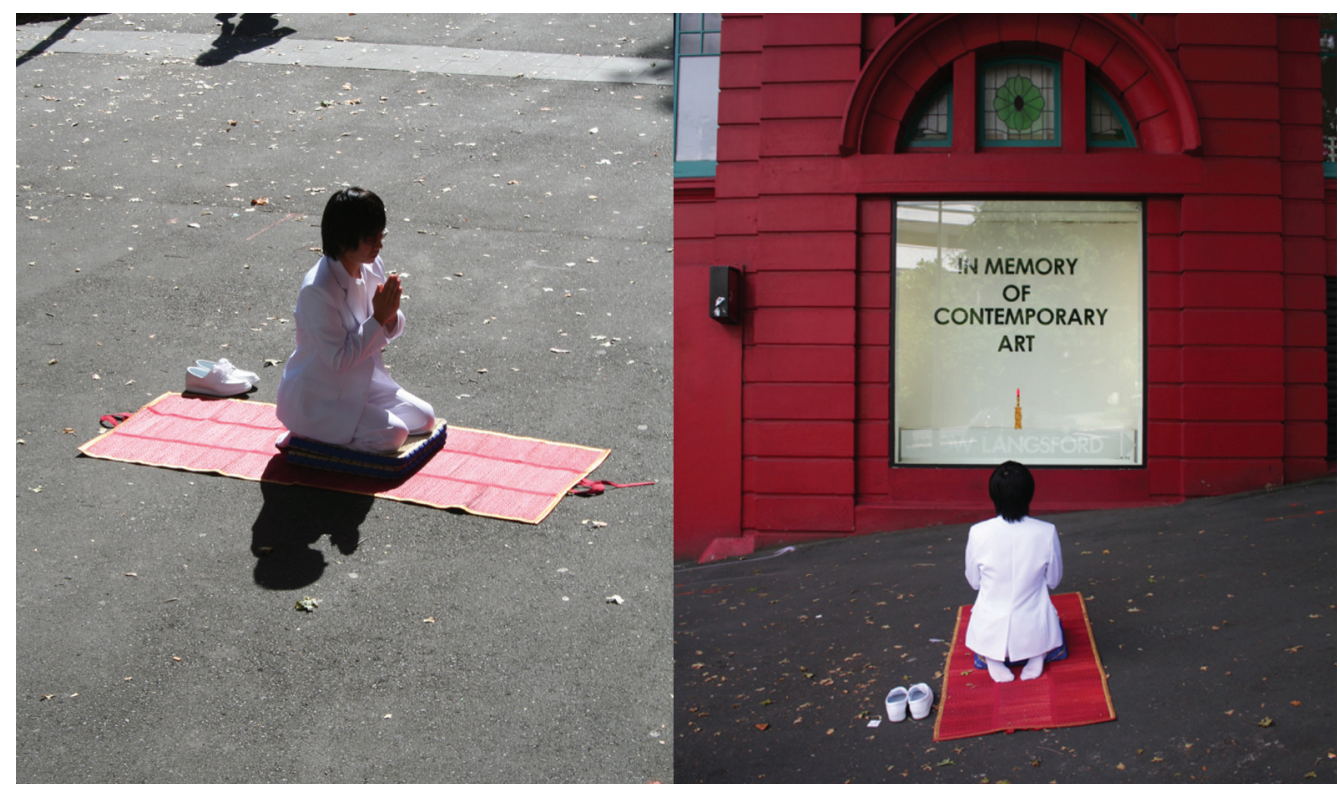

Figure 5. In Memory of Contemporary Art, Gow Langsford Gallery, Auckland, New Zealand.

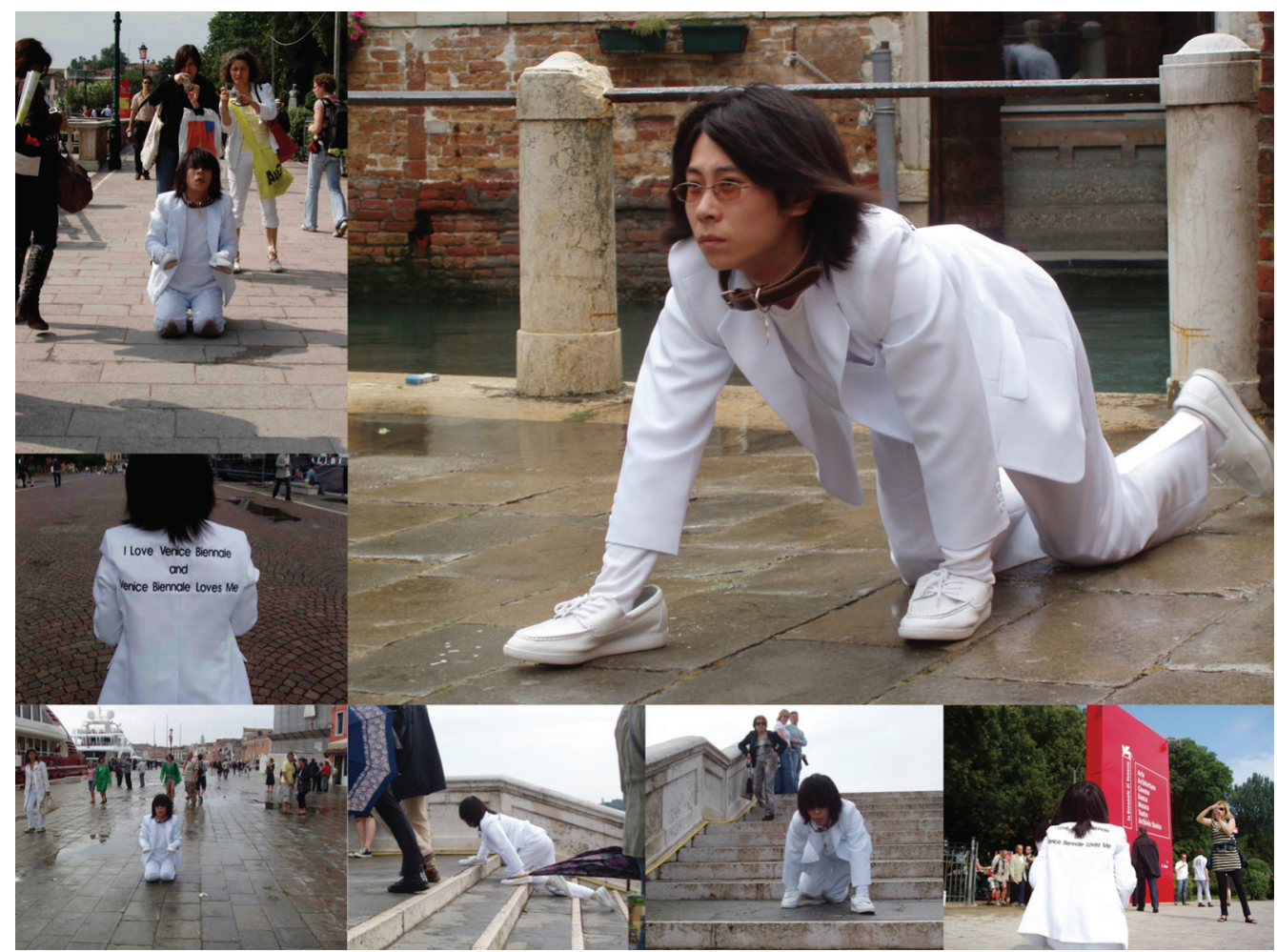

Figure 6. I Love Venice Biennale and Venice Biennale Loves Me, 52nd Venice Biennale. 


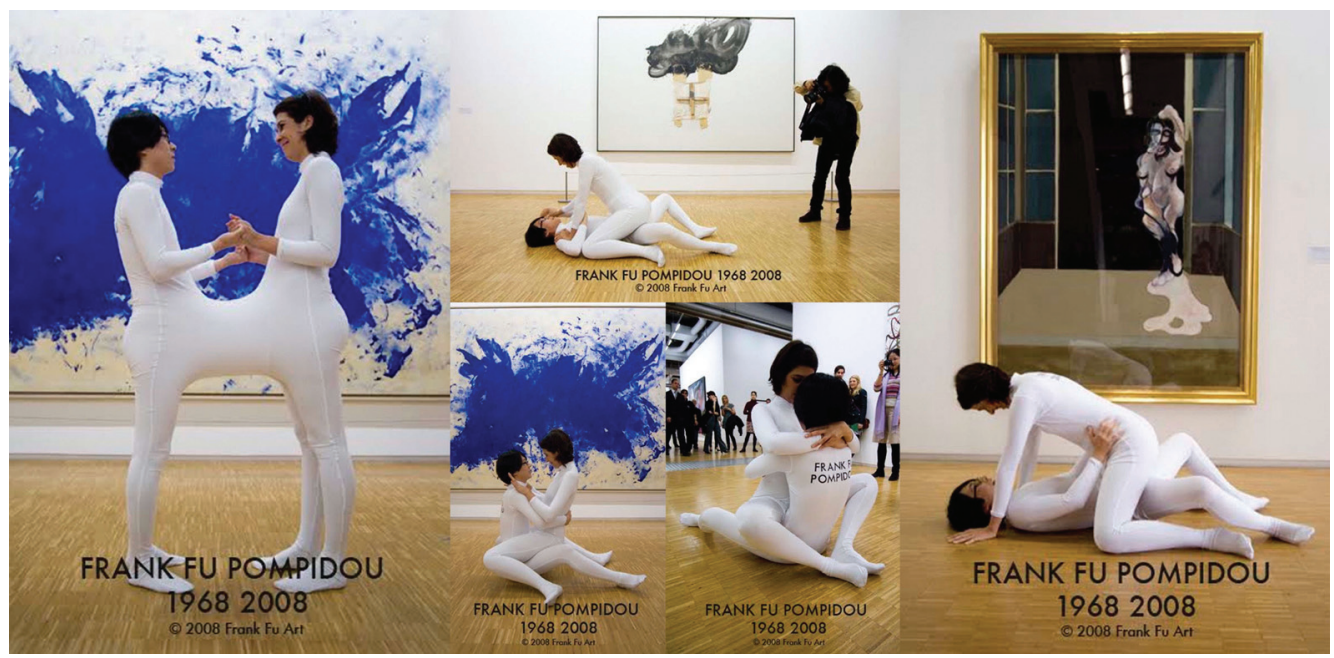

Figure 7. Frank Fu Pompidou 1968 2008, Centre Pompidou, Paris.
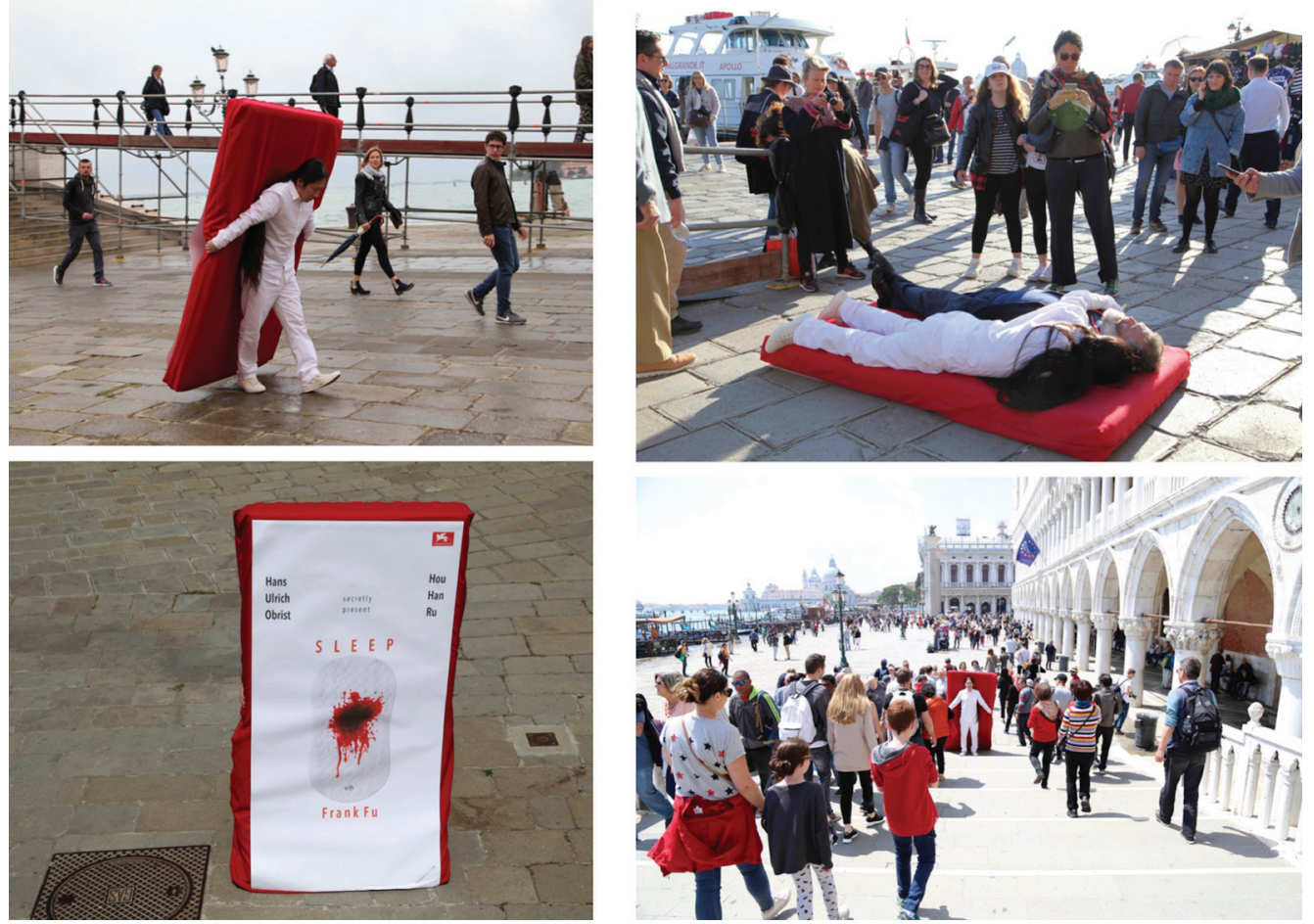

Figure 8. Sleep with Frank Fu, 57th Venice Biennale. 


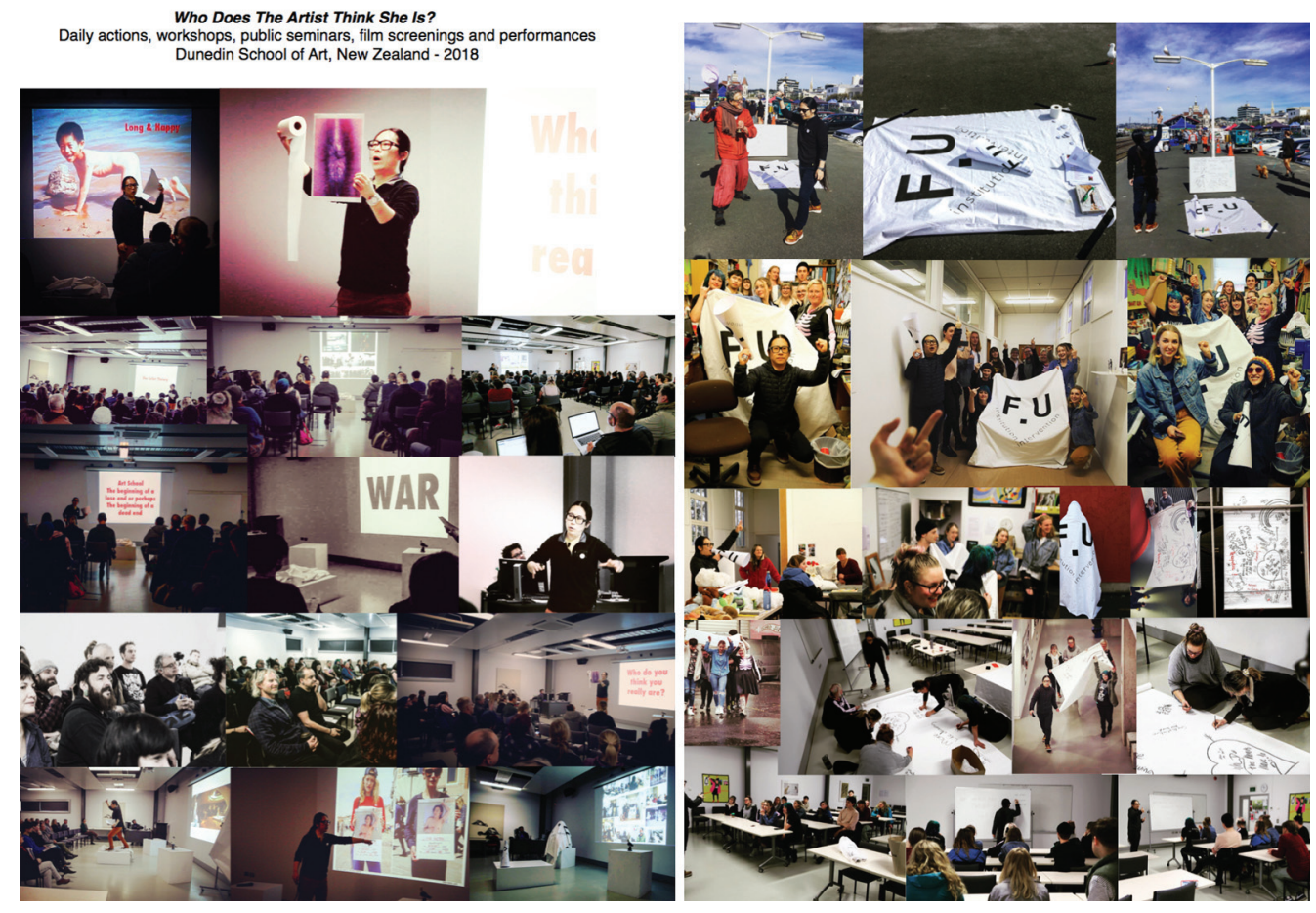

Figure 9. Who Does The Artist Think She Is? Dunedin School of Art, New Zealand.

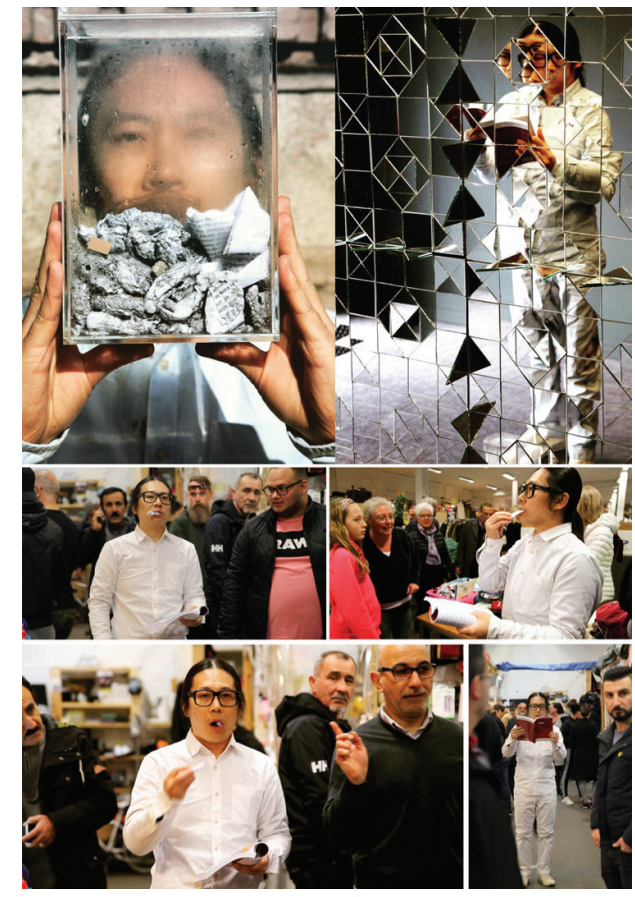

Figure 10. Deleuze and the City, Sweden. 